\title{
Exploitative Competition and Risk of Parasitism in Two Host Ant Species: The Roles of Habitat Complexity, Body Size, and Behavioral Dominance
}

\author{
Elliot B. Wilkinson and Donald H. Feener Jr. \\ Department of Biology, University of Utah, 257 South 1400 East, Salt Lake City, UT 84112, USA \\ Correspondence should be addressed to Elliot B. Wilkinson, ebwilkinson@yahoo.com
}

Received 24 August 2011; Revised 31 October 2011; Accepted 4 November 2011

Academic Editor: Volker Witte

Copyright ( 2012 E. B. Wilkinson and D. H. Feener Jr. This is an open access article distributed under the Creative Commons Attribution License, which permits unrestricted use, distribution, and reproduction in any medium, provided the original work is properly cited.

\begin{abstract}
Habitat structural complexity can slow resource discovery by ants but can also lower the risk of parasitism during foraging. The relative importance of these two ecological facets of habitat complexity may differ in a species-specific manner and thus may be important in the outcome of exploitative competition over food resources. For the host ant species Pheidole diversipilosa and $P$. bicarinata, we used in situ experimental manipulations to explore whether the effects of habitat complexity on exploitative competition depended on host body size and behavioral dominance, two characteristics likely to affect mobility and utilization of refuge from specialist Dipteran parasitoids (Apocephalus orthocladius and A. pugilist, resp.). We found that habitat complexity affected the resource discovery and harvest components of exploitative competition in an opposing fashion for each species and discuss these results in light of the differences in body size and behavioral dominance between the two hosts.
\end{abstract}

\section{Introduction}

Characteristics of habitats in which animals forage influence their mobility, ability to compete, and the likelihood of encountering predators, among other things. The structural complexity of a habitat can act on several aspects of animal foraging simultaneously. In particular, exploitative competition or the consumption of a common resource without direct competitive interaction may be directly affected by habitat complexity because it constrains animal movement in a species-specific manner [1]. Architecturally complex substrates often take more energy and time to traverse [25], which can reduce a species' ability to find and efficiently harvest a resource. A given degree of habitat complexity will be more difficult for relatively small species to traverse because they must move around or through the substrate, instead of over it [1]. As a result, habitat complexity can mediate exploitative competition for a common resource because species of different sizes are differentially affected.

Although habitat complexity may have negative effects on exploitative competitive ability by constraining animal movement, it may also have positive indirect effects on competitive ability by providing refuge from predators or parasitoids during resource acquisition. Numerous studies on a wide range of taxa have noted the importance of habitat complexity in providing refuge from predators ([6$13]$, but see $[14,15]$, e.g., of habitat complexity increasing predation). By impeding movement and providing refuge, habitat complexity may have opposing effects on resource discovery and acquisition, but the degree to which this is true may depend on species-specific characteristics such as body size or use of refuge from predators.

Ant communities are well suited for studying the role of habitat complexity in exploitative resource competition and escape from predators. Evidence suggests that exploitative competition between species has fitness consequences and is important in determining community composition [16-19]. Ants exhibit a wide range of body sizes [1], with larger ants being able to navigate complexity in the microhabitat more easily than small ants [20-23]. Increased habitat complexity does not appear to have an energetic cost to foragers [24], but does increase the time required to harvest resources and necessarily decreases harvest rate [25]. 
Ant communities are not traditionally considered to be structured by top-down forces from predators. However, community composition can be influenced by specialist Dipteran parasitoids (Apocephalus: Phoridae) that attack host ant species, induce behavioral responses in their hosts, and alter the outcome of interspecific competition in the community [26-32]. Habitat complexity has been shown to benefit the host ant species Pheidole diversipilosa and $P$. bicarinata during interference competition with nonhost ant species by providing refuge from parasitoids. Refuge allows hosts to maintain similar numbers of soldiers during head-to-head competition as in competitive bouts without parasitoids [13]. These two host ants cooccur in the same habitat and are dominant to most other ants in the community, but $P$. bicarinata is behaviorally subordinate to $P$. diversipilosa [30]. This difference in dominance has the potential to impact benefits derived from habitat complexity during exploitative competition.

Previous research indicates that $P$. diversipilosa wins a majority of contests, has access to the majority of resources, and experiences a resource environment that is not restricted by competition [29]. If such a host is attacked by its specialist parasitoid while exploiting an uncontested resource, it can simply abandon the resource, wait for parasitoids to leave, and return to the resource at a later time [33]. As a result, any refuge provided by habitat complexity would have marginal benefit to the colony during exploitative competition.

Predictions are different for the more subordinate species, P. bicarinata. Subordinate species only have access to a limited proportion of total available resources because they often lose resources to dominants [29]. Previous work has shown that subordinate hosts simply cannot afford to leave a resource when parasitoids arrive because successful foraging bouts are too rare [33]. For subordinates, a higher mortality risk must be accepted in order to satisfy energy requirements. Work on damselfly, passerine bird and ant communities has demonstrated that solutions to this ecological trade-off have evolutionary repercussions: subordinate competitors or species with higher resource requirements display little predator avoidance regardless of any pressure from dominant competitors [33-35]. Such observations have led to the hypothesis that subordinate species, who typically experience a more limited resource environment than dominants, will sacrifice predator avoidance to a greater extent than dominants in order to meet energy requirements $[33,36$, 37]. While harvesting uncontested resources, subordinate hosts are likely to benefit from refuge provided by habitat complexity to a greater extent than dominant hosts because subordinates under attack by parasitoids must continue to forage even when resources are not contested by competitors, whereas dominants can avoid parasitism by returning to the nest.

The ecological and evolutionary consequences of host dominance discussed above suggest that benefits derived from habitat complexity may depend on whether foraging is occurring in an interference or exploitative competitive context. The benefits derived from habitat complexity during interference competition (head-to-head competition for resources) are investigated in a previous study [13]. In con- trast, this study focuses on whether habitat complexity affects the exploitative component of competition (depression of the resource base in the absence of competitors). We explored the benefits derived from habitat complexity separately in interference and exploitative contexts because parasitoids have a greater impact on hosts engaged in interference competition (versus exploitative harvest of uncontested resources), due to a positive feedback between recruitment pheromones used during defense of resources and parasitoid behavior [29].

In addition, this study expands upon a previous study [13] by exploring whether habitat complexity affects the "discovery" and "harvest" components of exploitative competition separately. The effects of habitat complexity on each component of exploitative competition are interpreted in light of the body size and behavioral dominance of two host ant species. Of the two focal species, $P$. diversipilosa is approximately twice as large as $P$. bicarinata (workers: 0.12 versus $0.05 \mathrm{mg}$, resp.; soldiers: 0.44 versus $0.26 \mathrm{mg}$, resp.), and wins $15 \%$ more of its interactions with all other species in the local assemblage [30]. First, we determine whether habitat complexity influences the time it takes each host species to find resources (the "discovery" component of exploitative competition, [38]). Second, we ask whether the benefits hosts receive from refuge during harvest of uncontested resources (the "harvest" component of exploitative competition) depends on their dominance within the community. Benefits provided by habitat complexity during harvest of uncontested resources are measured in terms of the number of soldier ants because (1) soldier ants are crucial for the defense and harvest of large resources and (2) only soldiers are attacked by parasitoids. We then interpret our findings in the context of variation in habitat complexity.

\section{Materials and Methods}

2.1. Study Site and System. This study was conducted in oak, pine, and juniper woodlands in the Chiricahua Mountains of Southeast Arizona. The two focal ant species $P$. diversipilosa and $P$. bicarinata coexist in this habitat and are hosts to species-specific parasitoids (Apocephalus orthocladius and A. pugilist, resp., [39]). In July-August of 2003, P. diversipilosa was studied on National Forest land surrounding the Southwestern Research Station $\left(31^{\circ} 52^{\prime} \mathrm{N} 109^{\circ} 14^{\prime} \mathrm{W}\right)$. In AugustSeptember of 2004, P. bicarinata was studied nearby on land owned by the Southwestern Research Station $\left(31^{\circ} 53^{\prime} \mathrm{N}\right.$ $\left.109^{\circ} 12^{\prime} \mathrm{W}\right)$. Colonies of $P$. diversipilosa, $P$. bicarinata, and their respective parasitoids are found at both of these sites within meters of each other, but their relative abundances at each site differ (see Section 4).

2.2. Experimental Design. To investigate how habitat complexity affects exploitative competition for resources and host-parasitoid interactions, we forced field colonies to forage up into plastic bins and recorded their behavior under different levels of habitat complexity and parasitism. Cookie baits measuring $2 \times 2 \mathrm{~cm}$ were placed $50 \mathrm{~cm}$ away from the nest entrance, and the number of soldiers harvesting and 
defending these baits was recorded every 10 minutes for 2.5 hours in all treatments. Cookie baits are examples of large resources that require soldiers to break them into small pieces for efficient transport by workers. Placing baits $50 \mathrm{~cm}$ away from colony entrances ensured that baits were discovered and that colonies traversed a distance during which they were susceptible to parasitoid attack.

Foraging bins were $30 \times 60 \mathrm{~cm}$ Sterilite storage containers, and had a $6 \mathrm{~cm}$ diameter hole at one end that could be placed directly over colony nest entrances. Using foraging bins allowed us to (1) minimize disturbance around nest sites and control exactly which resources hosts were harvesting and (2) introduce or exclude parasitoids from treatments using bridal veil to cover the foraging bin. We used soldier number as a response variable because soldiers (1) are able to carve up large resources for transport to the nest by workers, and thus are critical to harvesting resources, (2) can defend resources against competitors, and (3) are the only caste attacked by parasitoids in this system. We also recorded the time it took colonies to discover cookie baits.

We used a multifactor design with two levels of habitat complexity (complex or simple) and parasitoid exposure (parasitoids present or absent). Complex habitat treatments contained $5000 \mathrm{~cm}^{3}$ of leaf litter that had been ovendried for $72 \mathrm{~h}$, while simple habitat treatments occurred in empty foraging bins. The addition of leaf litter closely approximated average leaf litter depth found in habitat where both species coexisted. Parasitoids were captured by aspiration during recruitment events instigated at unused host colonies nearby. In parasitoid-present treatments, two parasitoids were introduced after soldiers had recruited to resources. Foraging bins were covered tightly with bridal veil in all treatments to ensure that parasitoids could not escape from parasitoid-present treatments and that parasitoids could not gain access to parasitoid-absent treatments.

Treatments were replicated on seven colonies of $P$. diversipilosa and eight colonies of $P$. bicarinata. The experiment was performed in areas where $P$. diversipilos $a$ and its specialist parasitoid $A$. orthocladius cooccurred with $P$. bicarinata and its specialist parasitoid A. pugilist in order to control for the surrounding competitive environment. Colonies were randomly assigned the order in which they received treatments such that all colonies on a given trial day received different treatments. This allowed us to control for the effects of environmental variation and cumulative treatment effects. In addition, we rested colonies for two days between treatments to control for energetic state after foraging on cookies. It was not possible to monitor all colonies at once due to time constraints and distance between colonies, so all replicates were divided roughly into two groups, and groups experienced treatments within $24 \mathrm{~h}$ of each other to control for environmental conditions. All treatments were shaded to control for temperature and humidity differences between colony locations.

2.3. Analysis. Exploitative competition can generally be divided into two components: discovery and harvest of resources. To determine the impact of habitat complexity on resource discovery for each host, we conducted paired $t$-tests on the time it took hosts to discover cookie baits (TTD) in complex and simple habitat treatments. This experiment resembles a randomized block or repeated measures design, in which colonies are blocks and treatments are implemented within blocks. Since parasitoid treatments were not implemented until after hosts discovered cookie baits, TTD values were averaged across both levels of parasitism (e.g., for each complexity treatment, TTD values for each colony were averages of TTD in parasitoid absent and parasitoid present levels). Paired $t$-tests were then performed to compare each colony's average values for complex and simple habitats. To compare discovery speed between hosts within either simple or complex habitat treatments, we used two-sample $t$-tests because hosts were not intrinsically paired. To control for the multiple comparisons made within habitat complexity treatments and maintain an experiment-wide $\alpha$ of 0.05 , we used Bonferroni adjustments.

To determine whether the refuge benefits provided by habitat complexity during harvest of resources depend on host dominance level, we constructed a randomized block/ repeated measures General Linear Model to test for differences among treatments. For each host, post hoc comparisons among means were conducted using Tukey's HSD method with degrees of freedom appropriate for randomized block/repeated measures designs and 0.05 experiment-wide $\alpha$ levels. Replicate means were calculated by averaging recorded values of soldiers at cookie baits over the $2.5 \mathrm{~h}$ foraging period. Recorded values were averaged from the time colonies discovered the cookie bait for treatments without parasitoids, and from the point of parasitoid introduction for treatments with parasitoids. Means were transformed [log $($ mean +1$)$ ] to meet homogeneity of variance and normality assumptions.

\section{Results}

The time it took $P$. diversipilosa to discover cookie baits did not differ significantly between complex and simple habitat treatments $\left(t_{1,6}=-0.870, P>0.05\right.$; Figure 1$)$, although $P$. diversipilosa discovered resources slightly faster in complex habitat treatments. In contrast, $P$. bicarinata discovered resources in simple habitats much more quickly than in complex habitats $\left(t_{1,7}=5.276, P<0.005\right.$; Figure 1$)$. Within complex habitats, $P$. diversipilosa discovered resources more quickly than $P$. bicarinata $\left(t_{1,13}=2.538, P<0.05\right.$; Figure 1), but $P$. bicarinata discovered resources more quickly than $P$. diversipilosa in simple habitats $\left(t_{1,13}=-2.923, P<\right.$ 0.005 ).

For both $P$. diversipilosa and P. bicarinata, general linear models indicated that significant differences in the number of soldiers harvesting resources existed between at least two treatments $\left(F_{3,17}=5.070, P<0.05 ; F_{3,21}=4.139, P<0.05\right.$ resp.). P. diversipilosa maintained significantly more soldiers at resources in complex habitats without parasitoids than either complex or simple habitats with parasitoids (closed circle compared to closed and open triangles in Figure 2(a): $\left.Q_{t}=4.244, P<0.05 ; Q_{t}=4.683, P<0.05\right)$. There was a little 


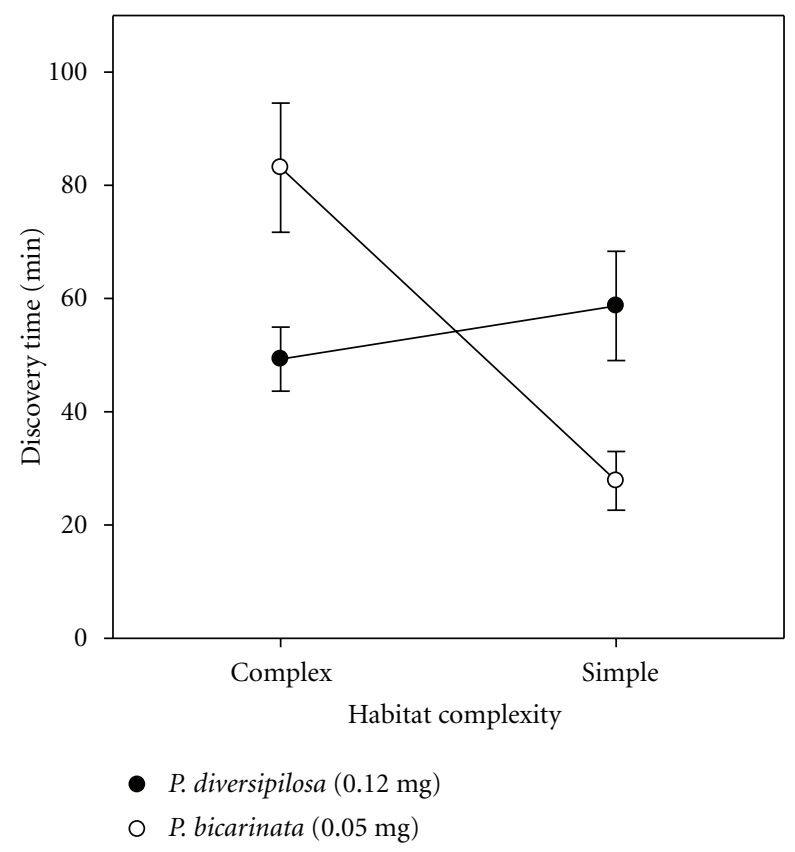

Figure 1: Differences in resource discovery time between $P$. diversipilosa and P. bicarinata in complex and simple habitats. Means and standard errors are presented.

difference in soldier number between simple and complex habitats without parasitoids (open and closed circles: $Q_{t}=$ $1.358, P>0.05)$. There was also no difference in soldier number between simple habitats without parasitoids and both simple and complex habitats with parasitoids (open circles compared to open and closed triangles: $Q_{t}=3.379$, $\left.P>0.05 ; Q_{t}=2.886, P>0.05\right)$.

$P$. bicarinata maintained significantly more soldiers at resources in complex and simple habitats without parasitoids than simple habitats with parasitoids (open and closed circles compared to open triangle in Figure 2(b): $Q_{t}=4.199, P<$ $\left.0.05 ; Q_{t}=4.191, P<0.05\right)$. In contrast, no difference in soldier number existed between complex and simple habitats without parasitoids and complex habitats with parasitoids (open and closed circles compared to closed triangles: $Q_{t}=$ 2.355, $\left.P>0.05 ; Q_{t}=2.347, P>0.05\right)$. Soldier number was also statistically indistinguishable between complexity levels in both parasitoid and no parasitoid treatments (open compared to closed triangles and open compared to closed circles: $\left.Q_{t}=1.844, P>0.05 ; Q_{t}=0.008, P>0.05\right)$.

\section{Discussion}

4.1. Exploitative Competition. For a given habitat complexity level, such as the leaf litter used in this study, smaller species perceive their environment as more rugose than larger species. This theory, known as the size-grain hypothesis, predicts that larger species will traverse a moderately rugose habitat with greater ease than smaller species [1]. Results on resource discovery time show that smaller P. bicarinata take longer to discover resources in complex habitats than do larger $P$. diversipilosa, which is consistent with the size-grain hypothesis. However, the observation that smaller P. bicarinata find resources in simple habitats more quickly than larger $P$. diversipilosa runs somewhat contrary to the predictions of the size-grain hypothesis. This observation suggests that, in addition to the limitations on movement predicted by the size-grain hypothesis, these two species either (1) differ in the degree to which they tolerate desiccation, (2) have different exploratory or recruitment strategies, or (3) exhibit differential sensory bias toward habitat complexity. First, differences in the degree to which species tolerate desiccation is not a plausible explanation for P. bicarinata discovering resources more quickly than $P$. diversipilosa in simple habitats because smaller ants such as $P$. bicarinata are more sensitive to desiccation stress than larger ants, and soil temperatures are much higher in more open, simplified environments [40-44]. Physiological limitations are also not a plausible explanation in the context of our experimental setup because physiological conditions between treatments were controlled (see Section 2). Second, $P$. diversipilosa and $P$. bicarinata may differ in their exploratory [45] or recruitment behaviors [46]. Unfortunately, the small scale of our experimental arena caused a rapid attenuation of recruitment curves, making insight into exploratory and recruitment behavior difficult in this study. Further work should be conducted to determine whether differences in exploratory or recruitment behavior can explain $P$. bicarinata discovering resources more quickly than $P$. diversipilosa in simple habitats. Finally, $P$. diversipilosa and $P$. bicarinata may exhibit differential sensory bias towards habitat complexity, a possibility that is discussed in detail below. Regardless of the mechanism behind these results, the ultimate consequence is that smaller $P$. bicarinata can discover resources faster in simple habitats, while larger $P$. diversipilosa can discover resources faster in complex habitats. Thus, habitat complexity has important but contrasting effects on the resource discovery component of exploitative competition for both species.

During initial attempts to find host colonies for this study, $44 \%$ of $P$. bicarinata and $64 \%$ of $P$. diversipilosa foraging bouts to cookie baits went unchallenged (data not shown). Thus refuge from parasitoids during uncontested harvest of resources may have important fitness consequences. $P$. diversipilosa and P. bicarinata harvesting resources in the absence of direct competition respond differently to habitat complexity, and this difference is best explained by the parasitoid avoidance behavior and dominance of each host. We predicted that $P$. diversipilosa, being behaviorally more dominant and having access to the majority of resources, would abandon uncontested resources when under attack by parasitoids regardless of the presence of refuge in complex habitats. This prediction follows from the resource loss-predation trade-off suggested to exist in a variety of systems $[33,36,37]$. We found that $P$. diversipilosa under attack by parasitoids do abandon uncontested resources regardless of whether refuge from habitat complexity is present. However, we also found that the number of soldiers $P$. diversipilosa maintains at resources in simple habitats without parasitoids is not statistically distinguishable from the number of soldiers maintained in simple habitats with parasitoids. 
A lower physiological threshold for open habitats is one explanation for this pattern but is unlikely for reasons explained above. In addition, if desiccation tolerance were solely responsible for the observed foraging patterns of $P$. diversipilosa during exploitative competition, significant differences between complex habitat treatments in the presence and absence parasitoids should not exist. However, we cannot rule out the role of desiccation tolerance in $P$. diversipliosa foraging behavior. A more plausible explanation is that $P$. diversipilosa exhibits a sensory bias towards habitat complexity and is less willing to forage in any habitat that does not offer refuge from parasitoids. Numerous studies on a wide range of taxa suggest that animals make patch choices based on perceived predation risk ([47] and references therein, [48-50]). Work on vole, deer mouse and passerine bird populations suggests that competitive dominants may choose to forage in habitats with less predation risk, thereby forcing subordinates to forage in habitats with greater predation risk [50-53]. These patch choices take place in ecological time and are considered solutions to the problem of maximizing energy intake while minimizing mortality risk.

As predicted by the resource loss-predation trade-off, subordinates must accept a higher mortality in order to satisfy energy requirements. Therefore, we predicted that $P$. bicarinata under attack by parasitoids would benefit from refuge even while foraging on uncontested resources. The number of $P$. bicarinata soldiers at resources in complex habitats was similar regardless of parasitoid presence, but soldier number in simple habitats with parasitoids was much lower than without parasitoids. These observations support the predictions of the resource loss-predation trade off and suggest that refuge benefits associated with habitat complexity depend on host dominance during exploitative competition. Subordinate hosts harvesting uncontested resources benefit from habitat complexity because their need for resources does not allow them to avoid parasitism by ceasing foraging. In contrast, dominant hosts harvesting uncontested resources receive no benefit from habitat complexity because they can afford to cease foraging in the presence of parasitoids. The potential for resource loss increases when resources are directly contested by competitors (interference competition). As the potential for resource loss increases during interference competition, dominant hosts should become more willing to accept the risk of parasitism in order to retain resources, and refuge provided by habitat complexity may allow hosts to strike a balance between retaining resources and risking mortality. Prior work in this system has shown that $P$. diversipilosa under attack by parasitoids will not abandon resources if they are directly contested by competitors, as long as habitat complexity provides some refuge from attacking parasitoids [13]. This study expands upon previous work [13] by demonstrating that behavioral dominance and refuge provided by habitat complexity interact to influence how species balance the resource loss-predation trade-off in different competitive contexts. The acts of discovering resources and harvesting resources in the absence of competitors are two important components of exploitative competition between the focal species of this study. Habitat complexity provides an advantage to $P$. diversipilosa during the discovery phase of exploitative competition because P. diversipilosa is larger and can traverse complex habitats more easily than $P . b i$ carinata. The opposite is true while harvesting resources: habitat complexity provides an important refuge benefit to $P$. bicarinata, but no refuge benefit to $P$. diversipilosa. During exploitative competition, habitat complexity plays a dual role in impeding movement and providing refuge. These mechanisms work in opposing manners in this system because the focal species differ in body size and behavioral dominance. The degree to which the discovery and harvest components of exploitative competition are opposing will depend on the relative strength with which habitat complexity impedes movement and offers refuge for $P$. diversipilosa and P. bicarinata.

4.2. Impact of Natural Heterogeneity on Movement and Benefits from Refuge. For ants, the degree to which movement is impeded by habitat complexity depends largely on the abundance and quality of litter on the ground surface. Natural heterogeneity in habitat complexity could lead to local pockets in which movement was strongly impeded by habitat complexity, favoring $P$. diversipilosa's resource discovery abilities, and other pockets where movement was unimpeded, favoring $P$. bicarinata's discovery abilities. In extremely heterogeneous environments, the relative discovery abilities of both species may, therefore, be similar when summed across the community. Further work is needed to determine whether natural heterogeneity in habitat complexity could facilitate coexistence between these host species.

The degree to which habitat complexity provides refuge depends both on variation in litter and on the abundance of parasitoids. While under attack by a constant number of parasitoids, $P$. bicarinata benefits more from refuge than $P$. diversipilosa (Figure 2). If there is reliable parasitoid pressure on both hosts, $P$. bicarinata would experience a greater relative benefit from refuge. Working in the same system, LeBrun and Feener [29] found that parasitoids discovered $P$. diversipilosa exploiting resources in the absence of competitors $\sim 50 \%$ of the time. Parasitoid discovery of $P$. bicarinata is less predictable, as A. pugilist exhibits wide fluctuations in abundance through space and time, but is rarely more than $50 \%$ [33]. Based on observed parasitoid abundance for each host, it appears that the potential to benefit from refuge is greater for $P$. bicarinata. Pockets of low habitat complexity will not counteract benefits that $P$. bicarinata receives from areas nearby with higher habitat complexity because, unlike $P$. diversipilosa, $P$. bicarinata forages willingly in simplified habitats, and also unlike $P$. diversipilosa, $P$. bicarinata maintains some foraging presence at resources regardless of whether refuge from parasitoids is available (see Figure 2).

4.3. Conclusions. While P. diversipilosa should have greater relative discovery abilities in complex habitats, natural heterogeneity in structural complexity will minimize this advantage by favoring $P$. bicarinata in simpler habitats. P. bicarinata is also likely to benefit from refuge from parasitoids during harvest of uncontested resources to a greater degree than 
(a)

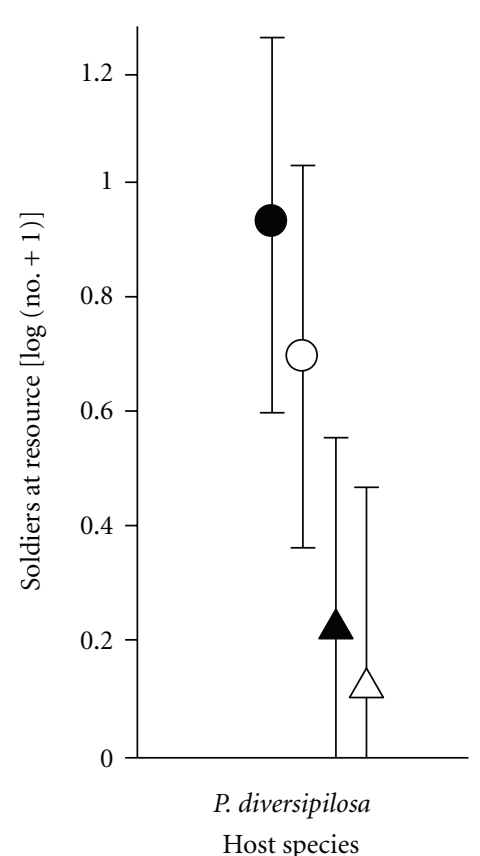

No parasite; simple

- No parasite; complex (b)

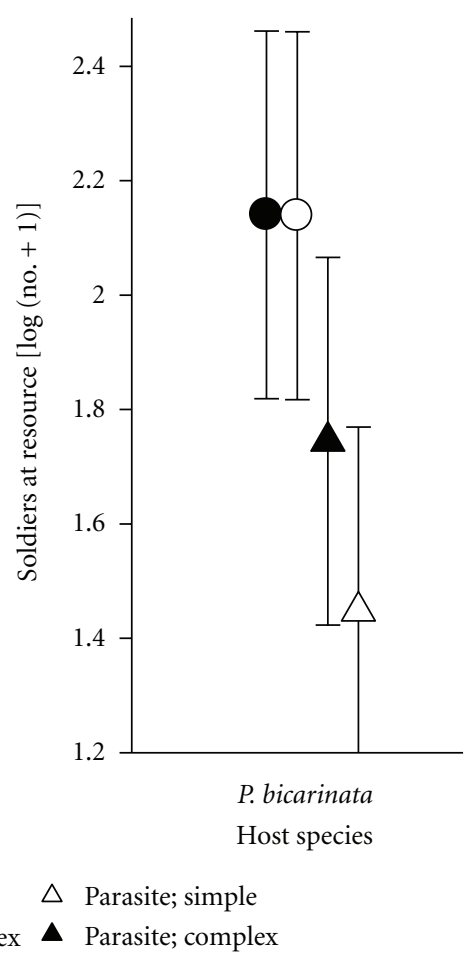

FIgURE 2: Number of (a) P. diversipilosa and (b) P. bicarinata soldiers harvesting resources in the absence of head-to-head competition when parasitoids are absent (circles) or present (triangles) in complex habitat (filled symbols) or simple habitat (empty symbols). Means and Tukey's minimum significant difference (MSD) comparison intervals are presented. Means whose comparison intervals overlap are not significantly different. Means whose comparison intervals do not overlap are significantly different at an experiment-wide $\alpha$ of 0.05 .

$P$. diversipilosa, and this advantage will not be affected by natural heterogeneity in structural complexity. These advantages in exploitative competitive ability experienced by $P$. bicarinata may partially explain why it is able to coexist along with $P$. diversipilosa, who is a superior interference competitor [29].

This study demonstrates how the dual roles of habitat complexity in impeding movement and providing refuge from parasitoids impact the exploitative competitive abilities of two host ant species. These two mechanisms by which habitat complexity mediates competition may function in an opposing manner because of differences in host body size and behavioral dominance. However, further work should be conducted to determine whether differences in exploratory or recruitment strategies offer additional insight into the effects of habitat complexity on each host $[45,46]$. Natural variation in habitat complexity or variation caused by disturbance such as fire [13] may impact the relative importance of these mechanisms for each host, the degree to which they are opposing, and therefore the potential for coexistence between these species. Knowledge of the prevalence of complex versus simple substrates within and between habitats is important for predicting the degree to which these mechanisms oppose each other, but is currently lacking.

\section{Acknowledgments}

The authors thank Jessica Pearce, Philipp Wiescher, and three reviewers for providing valuable comments on earlier drafts. Stefan Cover and Ed LeBrun helped identify host ants. This study benefited from the facilities of the Southwestern Research Station and the assistance of the Cuenca Los Ojos Foundation. The authors gratefully acknowledge support from the American Museum of Natural History Theodore Roosevelt Memorial Fund, Sigma Xi, the University of Utah Biology Department, the Associated Students of the University of Utah, NSF Dissertation improvement Grant (DEB04-07839), and NSF Research Grant (DEB03-16524).

\section{References}

[1] M. Kaspari and M. D. Weiser, "The size-grain hypothesis and interspecific scaling in ants," Functional Ecology, vol. 13, no. 4, pp. 530-538, 1999.

[2] J. A. Wiens, T. O. Crist, K. A. With, and B. T. Milne, "Fractal patterns of insect movement in microlandscape mosaics," Eco$\log y$, vol. 76, no. 2, pp. 663-666, 1995.

[3] T. O. Crist and J. A. Wiens, "Scale effects of vegetation on forager movement and seed harvesting by ants," Oikos, vol. 69, no. 1, pp. 37-46, 1994. 
[4] K. Cuddington and P. Yodzis, "Predator-prey dynamics and movement in fractal environments," American Naturalist, vol. 160, no. 1, pp. 119-134, 2002.

[5] A. Bernadou and V. Fourcassié, "Does substrate coarseness matter for foraging ants? An experiment with Lasius niger (Hymenoptera; Formicidae)," Journal of Insect Physiology, vol. 54, no. 3, pp. 534-542, 2008.

[6] T. C. J. Grubb and L. Greenwald, "Sparrows and a brushpile: foraging responses to different combinations of predation risk and energy cost," Animal Behaviour, vol. 30, no. 3, pp. 637640, 1982.

[7] J. Ekman, "Exposure and time use in willow tit flocks: the cost of subordination," Animal Behaviour, vol. 35, no. 2, pp. 445452, 1987.

[8] D. A. Andow and D. R. Prokrym, "Plant structural complexity and host-finding by a parasitoid," Oecologia, vol. 82, no. 2, pp. $162-165,1990$.

[9] T. L. Clark and F. J. Messina, "Plant architecture and the foraging success of ladybird beetles attacking the Russian wheat aphid," Entomologia Experimentalis et Applicata, vol. 86, no. 2, pp. 153-161, 1998.

[10] A. P. Norton, G. English-Loeb, and E. Belden, "Host plant manipulation of natural enemies: leaf domatia protect beneficial mites from insect predators," Oecologia, vol. 126, no. 4, pp. 535-542, 2001.

[11] B. A. Walther and A. G. Gosler, "The effects of food availability and distance to protective cover on the winter foraging behaviour of tits (Aves: Parus)," Oecologia, vol. 129, no. 2, pp. 312320, 2001.

[12] M. S. Hoddle, "The effect of prey species and environmental complexity on the functional response of Franklinothrips orizabensis: a test of the fractal foraging model," Ecological Entomology, vol. 28, no. 3, pp. 309-318, 2003.

[13] E. B. Wilkinson and D. H. Feener Jr., "Habitat complexity modifies ant-parasitoid interactions: implications for community dynamics and the role of disturbance," Oecologia, vol. 152, no. 1, pp. 151-161, 2007.

[14] L. A. Gosselin and E. Bourget, "Individual performance in relation to structural heterogeneity: the influence of substratum topography on an intertidal predator, Thais lapillus," Journal of Animal Ecology, vol. 58, pp. 278-304, 1989.

[15] D. L. Finke and R. F. Denno, "Intraguild predation diminished in complex-structured vegetation: implications for prey suppression," Ecology, vol. 83, no. 3, pp. 643-652, 2002.

[16] A. J. Pontin, "Further considerations of competition and the ecology of the ants Lasius flavus (F.) and L. niger (L.)," Journal of Animal Ecology, vol. 32, pp. 565-574, 1963.

[17] D. W. Davidson, R. S. Inouye, and J. H. Brown, "Granivory in a desert ecosystem: experimental evidence for indirect facilitation of ants by rodents," Ecology, vol. 65, no. 6, pp. 1780 1786, 1984.

[18] D. W. Davidson, "An experimental study of diffuse competition in harvester ants," American Naturalist, vol. 125, no. 4, pp. 500-506, 1985.

[19] B. Hölldobler and E. O. Wilson, The Ants, Bel knap Press of Harvard University Pres, Cambridge, Mass, USA, 1990.

[20] C. Gomiz and X. Espadaler, "Myrmecochorous dispersal distances: a world survey," Journal of Biogeography, vol. 25, no. 3, pp. 573-580, 1998.

[21] B. T. Bestelmeyer and J. A. Wiens, "Scavenging ant foraging behavior and variation in the scale of nutrient redistribution among semi-arid grasslands," Journal of Arid Environments, vol. 53, no. 3, pp. 373-386, 2003.
[22] J. H. Ness, J. L. Bronstein, A. N. Andersen, and J. N. Holland, "Ant body size predicts dispersal distance of ant-adapted seeds: implications of small-ant invasions," Ecology, vol. 85, no. 5, pp. 1244-1250, 2004.

[23] C. L. Parr, A. N. Andersen, C. Chastagnol, and C. Duffaud, "Savanna fires increase rates and distances of seed dispersal by ants," Oecologia, vol. 151, no. 1, pp. 33-41, 2007.

[24] J. H. Fewell, "Energetic and time costs of foraging in harvester ants, Pogonomyrmex occidentalis," Behavioral Ecology and Sociobiology, vol. 22, no. 6, pp. 401-408, 1988.

[25] J. A. Weier and D. H. Feener Jr., "Foraging in the seed-harvester ant genus Pogonomyrmex are energy costs important?" Behavioral Ecology and Sociobiology, vol. 36, no. 5, pp. 291300, 1995.

[26] D. H. Feener Jr., "Competition between ant species: outcome controlled by parasitic flies," Science, vol. 214, no. 4522, pp. 815-817, 1981.

[27] M. R. Orr, S. H. Seike, W. W. Benson, and L. E. Gilbert, "Flies suppress fire ants," Nature, vol. 373, pp. 292-293, 1995.

[28] M. R. Orr and S. H. Seike, "Parasitoids deter foraging by Argentine ants (Linepithema humile) in their native habitat in Brazil," Oecologia, vol. 117, no. 3, pp. 420-425, 1998.

[29] E. G. LeBrun and D. H. Feener, "Linked indirect effects in ant-phorid interactions: impacts on ant assemblage structure," Oecologia, vol. 133, no. 4, pp. 599-607, 2002.

[30] E. G. LeBrun, "Who is the top dog in ant communities? Resources, parasitoids, and multiple competitive hierarchies," Oecologia, vol. 142, no. 4, pp. 643-652, 2005.

[31] F. R. Adler, E. G. LeBrun, and D. H. Feener Jr., "Maintaining diversity in an ant community: modeling, extending, and testing the dominance-discovery trade-off," American Naturalist, vol. 169, no. 3, pp. 323-333, 2007.

[32] E. G. Lebrun and D. H. Feener Jr., "When trade-offs interact: balance of terror enforces dominance discovery trade-off in a local ant assemblage," Journal of Animal Ecology, vol. 76, no. 1, pp. 58-64, 2007.

[33] E. G. LeBrun, When to lose your head: ant-phorid fly interactions, community level impacts and evolutionary significance, Ph.D.dissertation, University of Utah, Salt Lake City, Utah, USA, 2003.

[34] R. Stoks and F. Johansson, "Trading off mortality risk against foraging effort in damselflies that differ in life cycle length," Oikos, vol. 91, no. 3, pp. 559-567, 2000.

[35] L. M. Carrascal and C. L. Alonso, "Habitat use under latent predation risk. A case study with wintering forest birds," Oikos, vol. 112, no. 1, pp. 51-62, 2006.

[36] F. R. Adler, "The balance of terror: an alternative mechanism for competitive trade-offs and its implications for invading species," American Naturalist, vol. 154, no. 5, pp. 497-509, 1999.

[37] J. Ekman, "Mass-dependence in the predation risk of unequal competitors; some models," Oikos, vol. 105, no. 1, pp. 109116, 2004.

[38] J. M. C. Pearce-Duvet, M. Moyano, F. R. Adler, and D. H. Feener Jr., "Fast food in ant communities: how competing species find resources," Oecologia, vol. 167, no. 1, pp. 229-240, 2011.

[39] B. V. Brown and E. G. LeBrun, "Ant-decapitating flies, Apocephalus, Subgenus Apocephalus Coquillett (Insecta: Diptera: Phoridae), of Arizona," Contributions in Science, vol. 519, pp. 1-24, 2010.

[40] J. R. B. Lighton and D. H. J. Feener, "Water-loss rate and cuticular permeability in foragers of the desert ant Pogonomyrmex 
rugosus," Physiological Zoology, vol. 62, no. 6, pp. 1232-1256, 1989.

[41] W. G. Hood and W. R. Tschinkel, "Desiccation resistance in arboreal and terrestrial ants," Physiological Entomology, vol. 15, no. 1, pp. 23-35, 1990.

[42] M. Kaspari, "Body size and microclimate use in neotropical granivorous ants," Oecologia, vol. 96, no. 4, pp. 500-507, 1993.

[43] X. Cerda, J. Retana, and S. Cros, "Critical thermal limits in Mediterranean ant species: trade-off between mortality risk and foraging performance," Functional Ecology, vol. 12, no. 1, pp. 45-55, 1998.

[44] S. P. Yanoviak and M. Kaspari, "Community structure and the habitat templet: ants in the tropical forest canopy and litter," Oikos, vol. 89, no. 2, pp. 259-266, 2000.

[45] C. Detrain, J. L. Deneubourg, S. Goss, and Y. Quinet, "Dynamics of collective exploration in the ant Pheidole pallidula," Psyche, vol. 98, pp. 21-32, 1991.

[46] A. Lenoir, A. Benoist, A. Hefetz, W. Francke, X. Cerda, and R. Boulay, "Trail-following behaviour in two Aphaenogaster ants," Chemoecology, vol. 21, pp. 83-88, 2011.

[47] S. L. Lima and L. M. Dill, "Behavioral decisions made under the risk of predation: a review and prospectus," Canadian Journal of Zoology, vol. 68, no. 4, pp. 619-640, 1990.

[48] P. Nonacs and L. M. Dill, "Mortality risk vs. food quality tradeoffs in a common currency: ant patch preferences," Ecology, vol. 71, no. 5, pp. 1886-1892, 1990.

[49] A. Bouskila, "Interactions between predation risk and competition: a field study of kangaroo rats and snakes," Ecology, vol. 76, no. 1, pp. 165-178, 1995.

[50] J. Jacob and J. S. Brown, "Microhabitat use, giving-up densities and temporal activity as short- and long-term anti-predator behaviors in common voles," Oikos, vol. 91, no. 1, pp. 131$138,2000$.

[51] J. J. Christian, "Social subordination, population density, and mammalian evolution," Science, vol. 168, no. 3927, pp. 84-90, 1970.

[52] M. A. Bowers and H. D. Smith, "Differential habitat utilization by sexes of the deermouse, Peromyscus maniculatus," Ecology, vol. 60, pp. 869-875, 1979.

[53] J. Suhonen, "Predation risk influences the use of foraging sites by tits," Ecology, vol. 74, no. 4, pp. 1197-1203, 1993. 

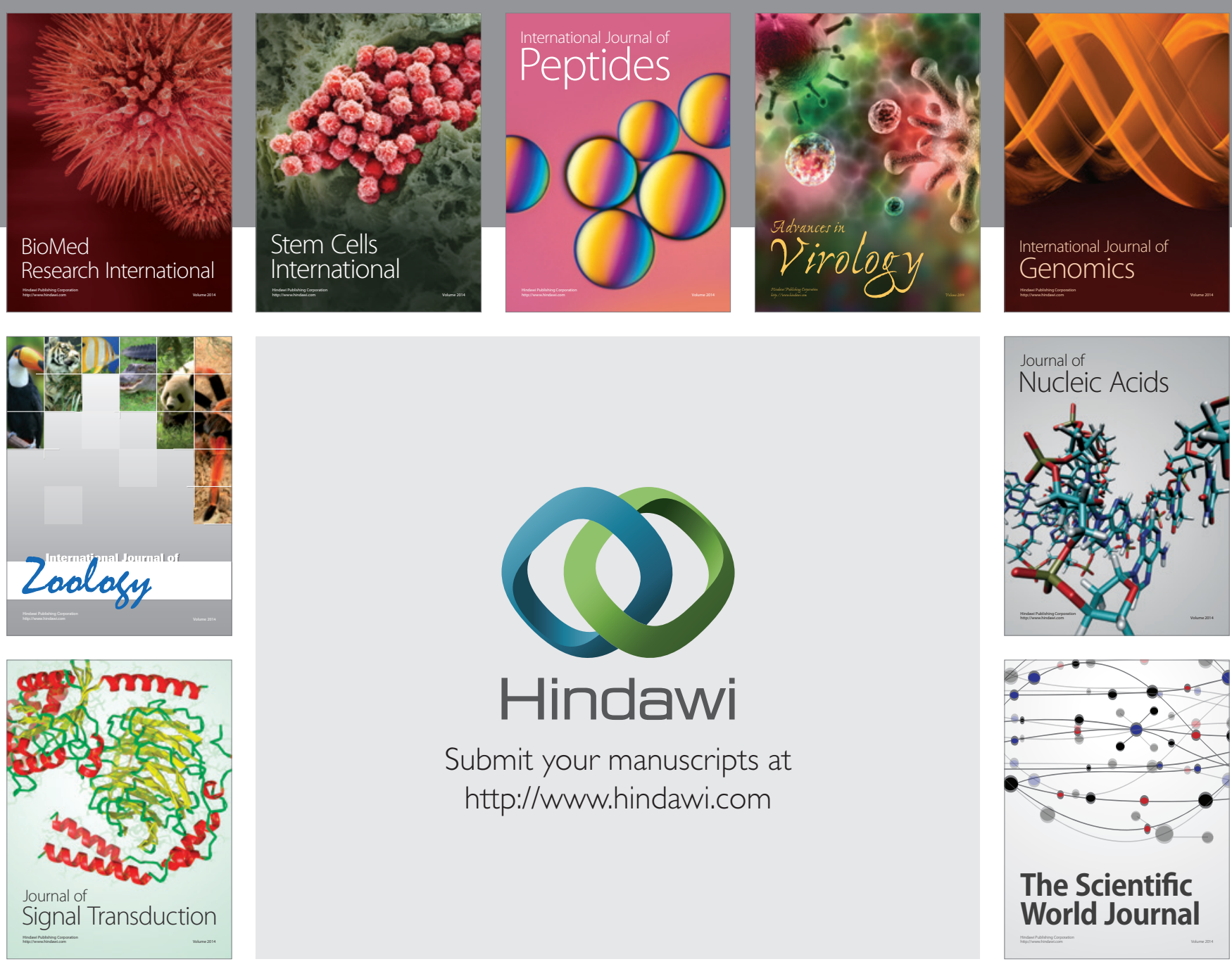

Submit your manuscripts at

http://www.hindawi.com
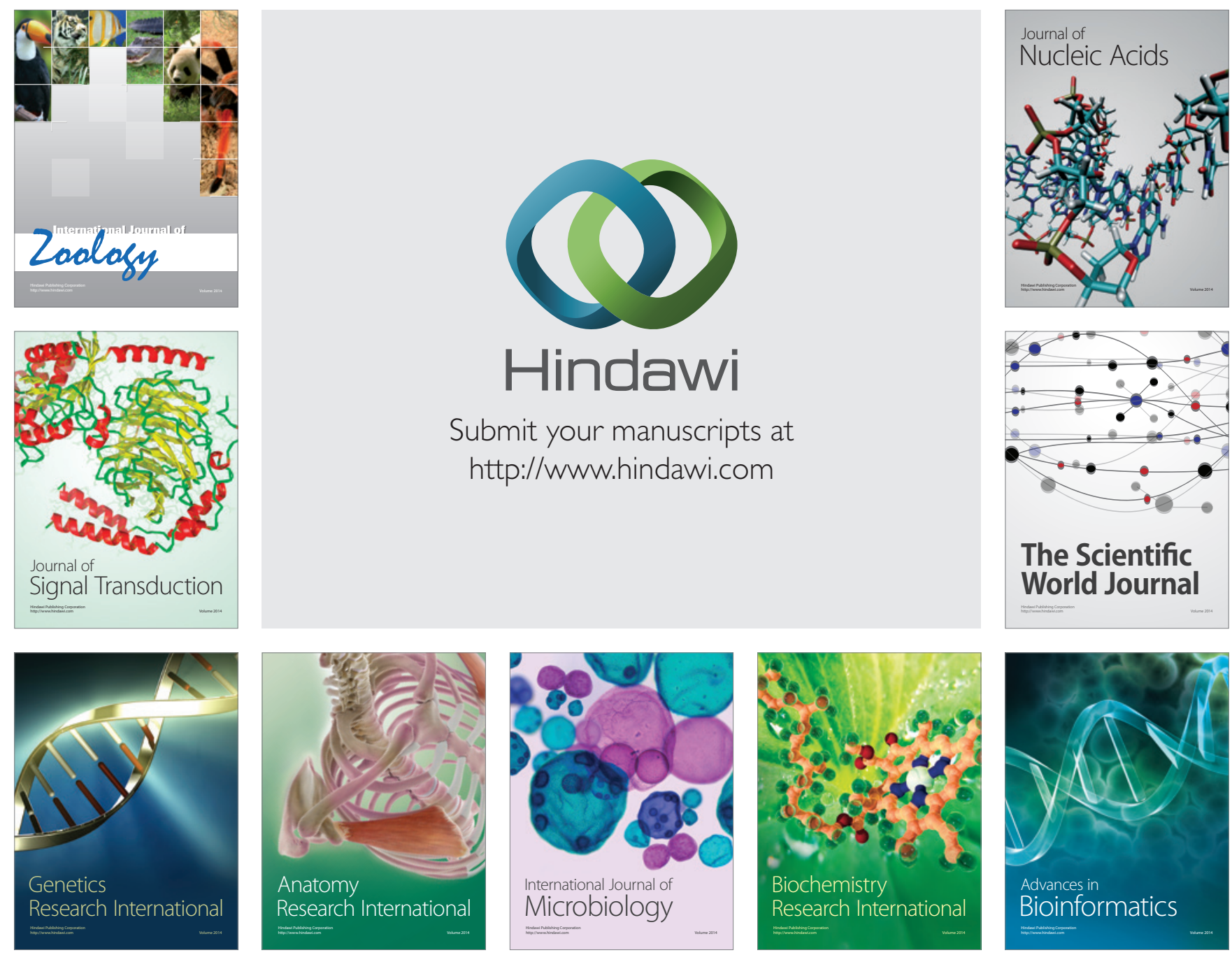

The Scientific World Journal
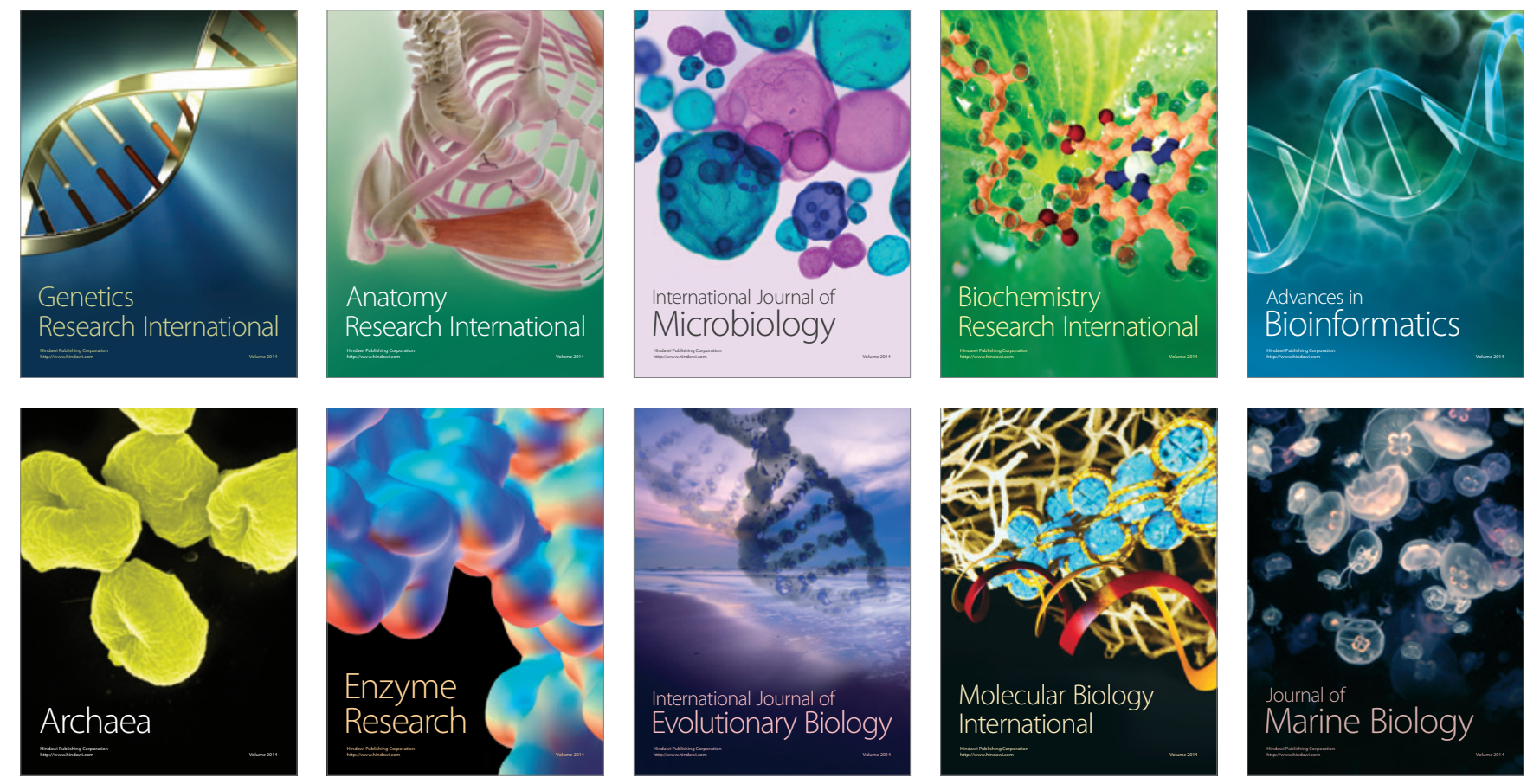